University of Nebraska - Lincoln

DigitalCommons@University of Nebraska - Lincoln

USDA National Wildlife Research Center - Staff

Publications

U.S. Department of Agriculture: Animal and Plant Health Inspection Service

2011

\title{
Reconciling sensory cues and varied consequences of avian repellents
}

\author{
Scott J. Werner \\ USDA-APHIS-Wildlife Services, scott.j.werner@aphis.usda.gov \\ Frederick D. Provenza \\ Utah State University
}

Follow this and additional works at: https://digitalcommons.unl.edu/icwdm_usdanwrc

Part of the Environmental Sciences Commons

Werner, Scott J. and Provenza, Frederick D., "Reconciling sensory cues and varied consequences of avian repellents" (2011). USDA National Wildlife Research Center - Staff Publications. 1070.

https://digitalcommons.unl.edu/icwdm_usdanwrc/1070

This Article is brought to you for free and open access by the U.S. Department of Agriculture: Animal and Plant Health Inspection Service at DigitalCommons@University of Nebraska - Lincoln. It has been accepted for inclusion in USDA National Wildlife Research Center - Staff Publications by an authorized administrator of DigitalCommons@University of Nebraska - Lincoln. 


\title{
Reconciling sensory cues and varied consequences of avian repellents
}

\author{
Scott J. Werner ${ }^{a, *}$, Frederick D. Provenza ${ }^{b}$ \\ a USDA/APHIS/ WS/ National Wildlife Research Center, 4101 LaPorte Avenue, Fort Collins, CO 80521-2154, United States \\ b Department of Wildland Resources, Utah State University, Logan, UT 84322-5230, United States
}

\section{A R T I C L E I N F O}

\section{Article history:}

Received 12 July 2010

Received in revised form 4 October 2010

Accepted 15 October 2010

\section{Keywords:}

Agelaius phoeniceus

Anthraquinone

Avoidance learning

Chemical repellent

Feeding behavior

Methiocarb

Methyl anthranilate

\begin{abstract}
A B S T R A C T
We learned previously that red-winged blackbirds (Agelaius phoeniceus) use affective processes to shift flavor preference, and cognitive associations (colors) to avoid food, subsequent to avoidance conditioning. We conducted three experiments with captive red-winged blackbirds to reconcile varied consequences of treated food with conditioned sensory cues. In Experiment 1, we compared food avoidance conditioned with lithium chloride $(\mathrm{LiCl})$ or naloxone hydrochloride $(\mathrm{NHCl})$ to evaluate cue-consequence specificity. All blackbirds conditioned with $\mathrm{LiCl}$ (gastrointestinal toxin) avoided the color (red) and flavor $(\mathrm{NaCl})$ of food experienced during conditioning; birds conditioned with $\mathrm{NHCl}$ (opioid antagonist) avoided only the color (not the flavor) of food subsequent to conditioning. In Experiment 2, we conditioned experimentally naïve blackbirds using free choice of colored (red) and flavored $(\mathrm{NaCl})$ food paired with an anthraquinone- (postingestive, cathartic purgative), methiocarb- (postingestive, cholinesterase inhibitor), or methyl anthranilate-based repellent (preingestive, trigeminal irritant). Birds conditioned with the postingestive repellents avoided the color and flavor of foods experienced during conditioning; methyl anthranilate conditioned only color (not flavor) avoidance. In Experiment 3, we used a third group of blackbirds to evaluate effects of novel comparison cues (blue, citric acid) subsequent to conditioning with red and $\mathrm{NaCl}$ paired with anthraquinone or methiocarb. Birds conditioned with the postingestive repellents did not avoid conditioned color or flavor cues when novel comparison cues were presented during the test. Thus, blackbirds cognitively associate pre- and postingestive consequences with visual cues, and reliably integrate visual and gustatory experience with postingestive consequences to procure nutrients and avoid toxins.
\end{abstract}

Published by Elsevier Inc.
Taste, smell, and sight help mammals and birds identify and discriminate among foods, but these senses play somewhat different roles in food preferences and food selection [1]. In Sprague-Dawley rats, flavor aversions are strongest when conditioned with illness caused by X-ray or lithium chloride ( $\mathrm{LiCl}$ ); aversions for audiovisual and spatial cues are strongest when conditioned with electric shock [2] or the pain-like effect of gallamine triethiodide and naloxone hydrochloride $(\mathrm{NHCl})$ [3]. Thus, sensory cues are specifically related to consequences of the subsequent reinforcer (i.e., cue-consequence specificity) [2]. Like the rat, bobwhite quail (Colinus virginianus) avoid flavored water subsequent to induced illness; unlike the rat, quail also avoided colored water subsequent to conditioning [4].

We learned previously that red-winged blackbirds (Agelaius phoeniceus) use affective processes to shift flavor preference, and cognitive associations (visual cues) to avoid food, subsequent to avoidance conditioning [5]. Unlike conditioned flavor avoidance, blackbirds were conditioned to avoid red food only when blue food was made familiar prior to conditioning [5]. Whereas no effective avian repellents are presently registered for agricultural applications

\footnotetext{
* Corresponding author. Tel.: +1970266 6136; fax: +1970 2666138. E-mail address: Scott.J.Werner@aphis.usda.gov (S.J. Werner).
}

in the United States, nonlethal repellents that effectively condition food avoidance are needed to reduce bird damages to newly planted and ripening crops. Thus, we recommended further evaluation of color-flavor-feedback relationships as part of avian repellent applications for reducing agricultural damage caused by blackbirds [5].

Based upon these findings, we wanted to investigate cueconsequence specificity among red-winged blackbirds using conditioned color and flavor cues, and varied consequences of treated food. To do so, we first compared avoidance conditioned with varied consequences via intraperitoneal administration. We then compared color and flavor avoidance conditioned via free choice of food treated with one of three avian repellents that exhibited varying modes of action. After evaluating cue-consequence specificity, we used novel comparison cues to test avoidance conditioned with the postingestive repellents.

We tested four hypotheses. If cue-consequence specificity $[2,3]$ is behaviorally adaptive for red-winged blackbirds (hypothesis 1 ), then we predicted that blackbirds would avoid flavor cues previously paired with gastrointestinal toxicosis and color cues previously paired with peripheral distress. The terms primary and secondary repellents have been used to characterize the modes of action of chemical repellents [6]. If primary repellents concurrently elicit reflexive withdrawal or escape behavior from specific or combined sensory 
stimuli, including odor, taste [7], and irritation [6] (hypothesis 2),we predicted that blackbirds would not avoid sensory cues previously paired with a trigeminal irritant. If secondary repellents subsequently yield learned avoidance via association between adverse postingestive effects and specific sensory cues, including taste, odor [7], and visual cues [6] (hypothesis 3), we predicted that blackbirds would avoid flavor and color cues previously paired with postingestive repellents. If blackbirds use flavor-feedback relationships (i.e., affective processes) to shift preference for both novel and familiar flavors [5] (hypothesis 4), we predicted that blackbirds would avoid novel flavor cues (not novel color cues) subsequent to conditioning with postingestive repellents.

\section{General methods}

\subsection{Bird subjects and testing facilities}

We conducted three feeding experiments with red-winged blackbirds at the outdoor animal research facility of the National Wildlife Research Center (NWRC) in Fort Collins, CO (USA). All birds were maintained in $4.9 \times 2.4 \times 2.4 \mathrm{~m}$ cages within an open-sided building for $\geq 2$ weeks prior to the experiments. During quarantine and holding, birds were provided free access to grit (sand) and maintenance food ( 2 millet: 1 milo: 1 safflower: 1 sunflower). Feeding experiments were conducted within individual cages $(0.9 \times 1.8 \times 0.9 \mathrm{~m})$ in an open-sided building. We provided water ad libitum to all birds throughout the experiments.

\subsection{Statistical analyses}

The dependent measure for preference testing associated with Experiments 1-3 was average daily consumption of colored or flavored rice throughout each 4-day test. Test consumption data for each conditioning group of Experiments 1-3 were subjected to a repeated-measures ANOVA. The random effect of our models was bird subjects, the between-subject effects were cues (test colors and flavors) and test groups, and the within-subject effect was test day. We evaluated the cue-by-test group and cue-by-test group-by-day interactions using the mixed procedure of SAS. We used Tukey's tests to separate the means of significant $(\alpha=0.05)$ interactions and descriptive statistics (mean $\pm \mathrm{SE}$ ) to summarize test consumption.

\section{Experiment one}

\subsection{Method}

We compared food avoidance conditioned with $\mathrm{LiCl}$ or $\mathrm{NHCl}$ to evaluate cue-consequence specificity among red-winged blackbirds. We previously observed baseline preference for red $(8.7 \pm 0.5 \mathrm{~g}$; average $\pm S E)$ vs blue rice $(0.5 \pm 0.4 \mathrm{~g})$, and baseline indifference for rice treated with $\mathrm{NaCl}(4.8 \pm 0.6 \mathrm{~g})$ vs citric acid (3.7 $\pm 0.6 \mathrm{~g})$ [5]. Thus, we paired induced gastrointestinal toxicosis $(\mathrm{LiCl})$ or opioid antagonism $(\mathrm{NHCl})$ with otherwise preferred (red) and neutral $(\mathrm{NaCl})$ sensory cues, and evaluated resultant color and flavor preferences. We captured 44 adult red-winged blackbirds (M) near Fort Collins, CO and transported them to NWRC. We transferred birds to individual cages following group quarantine and holding, and offered each bird unadulterated seed rice (ad libitum) in each of two food bowls for 5 days (Wed-Sun).

Following acclimation, we offered each bird two food bowls at 0800-0930 h, daily for four pretreatment days (Mon-Thur). Both food bowls contained $30 \mathrm{~g}$ of seed rice treated with blue pigment and citric acid (Table 1). Seed treatments included $100 \mathrm{~g}$ of blue \#2 (FD\&C aluminum lake dispersion; Roha U.S.A., L.L.C., St. Louis, MO), $150 \mathrm{~g}$ citric acid (Sigma-Aldrich, Inc., Bellefonte, PA), and 11 of water [5]. We uniformly applied aqueous solutions to $10 \mathrm{~kg}$ certified seed rice
Table 1

Schedule for conditioning ( $\mathrm{n}=22$ birds per conditioning group) and preference testing ( $n=11$ birds per test group) associated with conditioned avoidance among red-winged blackbirds in Experiment 1

\begin{tabular}{|c|c|c|c|}
\hline Experiment 1 & Color cue & Flavor cue & Consequence \\
\hline Pretreatment exposure (4 days) & Blue & Citric acid & \\
\hline \multicolumn{4}{|l|}{ Conditioning ( 1 day) } \\
\hline Group 1 & Red & $\mathrm{NaCl}$ & Lithium chloride \\
\hline Group 2 & Red & $\mathrm{NaCl}$ & $\begin{array}{l}\text { Naloxone } \\
\text { hydrochloride }\end{array}$ \\
\hline \multicolumn{4}{|l|}{ Preference testing (4 days) } \\
\hline \multicolumn{4}{|l|}{ Color preference test } \\
\hline Group 1A & Red vs blue & & \\
\hline Group 2A & Red vs blue & & \\
\hline \multicolumn{4}{|l|}{ Flavor preference test } \\
\hline Group 1B & & $\begin{array}{l}\mathrm{NaCl} \text { vs } \\
\text { citric acid }\end{array}$ & \\
\hline Group 2B & & $\begin{array}{l}\mathrm{NaCl} \text { vs } \\
\text { citric acid }\end{array}$ & \\
\hline
\end{tabular}

Conditioning groups 1 and 2 were conditioned with lithium chloride and naloxone hydrochloride, respectively, to avoid an otherwise preferred color (red) and neutral flavor $(\mathrm{NaCl})$. Daily food consumption in each of two food bowls was measured to evaluate color preference (test groups $1 \mathrm{~A}$ and $2 \mathrm{~A}$ ) and flavor preference (test groups $1 \mathrm{~B}$ and $2 \mathrm{~B}$ ) subsequent to conditioning.

(Louisiana State University Rice Research Station, Crowley) using a rotating mixer and household spray equipment for all seed treatments (Experiments 1-3). We randomly assigned conditioning treatments between two groups ( $\mathrm{n}=22$ birds per each of 2 conditioning groups) at the conclusion of the pretreatment.

We removed the pretreatment diet at 1600-1700 h on Thursday of the pretreatment (i.e., the day prior to conditioning). We offered two food bowls at $0430 \mathrm{~h}$ on the subsequent day (Friday). Both food bowls contained $30 \mathrm{~g}$ of seed rice treated with red pigment and $\mathrm{NaCl}$ (Table 1 ). Seed treatments included $100 \mathrm{~g}$ of red \#40 (FD\&C aluminum lake dispersion; Roha U.S.A., L.L.C.), $300 \mathrm{~g} \mathrm{NaCl}$ (Sigma-Aldrich, Inc.), and 11 of water [5]. For the purpose of avoidance conditioning, birds in conditioning group 1 received a $10 \mathrm{ml} / \mathrm{kg}$ intraperitoneal injection of $0.3 \mathrm{M} \mathrm{LiCl}$ and birds in conditioning group 2 received a $10 \mathrm{ml} / \mathrm{kg}$ intraperitoneal injection of $0.003 \mathrm{M} \mathrm{NHCl}$ between $0900-1000 \mathrm{~h}$ on Friday (Table 1). We measured rice consumption at $1100-1200 \mathrm{~h}$ on Friday. For each conditioning group, we ranked blackbirds based upon conditioning rice consumption and assigned them to one of two test groups ( $n=11$ birds per each of 4 test groups). We randomly assigned test cues among groups. We provided maintenance food ( 2 millet: 1 milo: 1 safflower: 1 sunflower; ad libitum) in each of two food bowls to all birds for three days (Fri-Sun) following conditioning, beginning $1100-1200$ h on Friday.

We offered two food bowls ( 30 g rice each) at 0800-0930 h, daily for four days of preference testing (Mon-Thur). For conditioning groups 1 and 2, we evaluated color preference with test groups $1 \mathrm{~A}$ and $2 \mathrm{~A}$, respectively (Table 1 ). We evaluated flavor preference with test groups $1 \mathrm{~B}$ and $2 \mathrm{~B}$. The north-south placement of food bowls was randomized on the first day and alternated on subsequent days of the preference test. We measured daily rice consumption, and accounted for rice spillage and desiccation throughout preference testing (Tue-Fri).

\subsection{Results and discussion}

Blackbirds conditioned with LiCl (Fig. 1a) manifest both conditioned color (Tukey $p=0.0001$ ) and flavor avoidance (Tukey $p=0.0001$ ) during the test. Average consumption of red and blue rice was $0 \mathrm{~g}$ $( \pm 0.0)$ and $10.2 \mathrm{~g}( \pm 0.4)$, respectively, and average consumption of rice treated with $\mathrm{NaCl}$ and citric acid was $0.2 \mathrm{~g}( \pm 0.2)$ and $10.7 \mathrm{~g}( \pm 0.3)$, respectively. Thus, we observed a cue-by-test group interaction for the red, $\mathrm{NaCl}$, LiCl conditioning group $(F(3,30)=624.83, p=0.0001)$. We also observed cue-test group-day interaction $(F(12,119)=3.71$, $p=0.0001$ ); blackbirds consumed more blue rice on day 3 (Tukey 
a

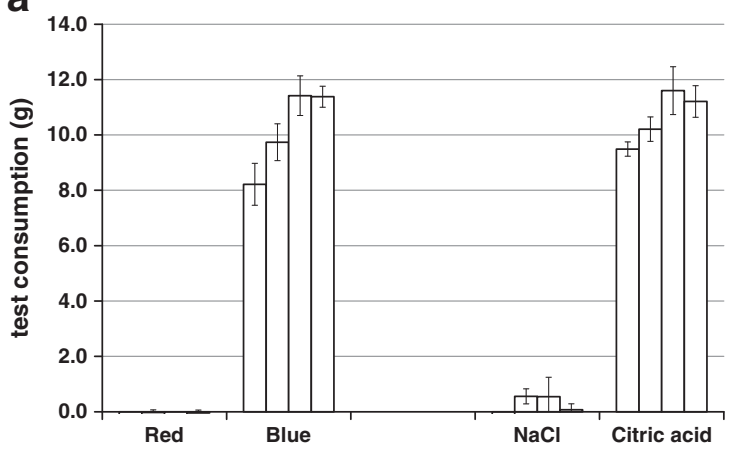

b

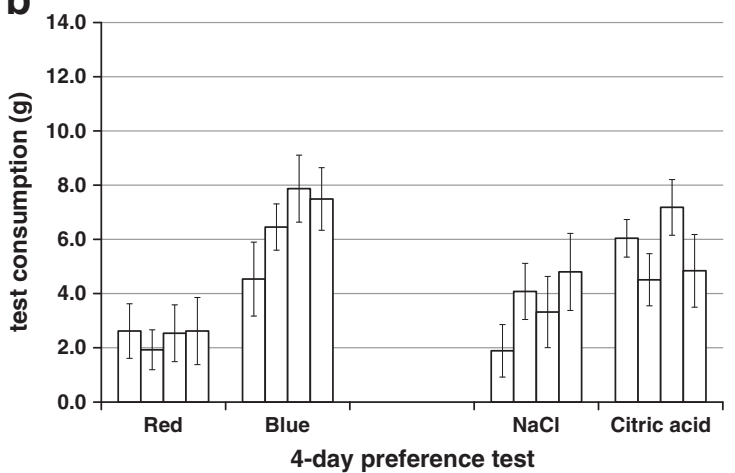

Fig. 1. Color and flavor preferences among red-winged blackbirds subsequent to intraperitoneal conditioning with (a) $\mathrm{LiCl}(\mathrm{n}=22)$ or $(\mathrm{b}) \mathrm{NHCl}(\mathrm{n}=21)$ paired with an otherwise preferred color (red) and an otherwise neutral flavor $(\mathrm{NaCl})$. Data represent average ( \pm SE) daily rice consumption during 4 test days subsequent to $\mathrm{LiCl}$ and $\mathrm{NHCl}$ conditioning.

$p=0.0006$ ) and day 4 of the test (Tukey $p=0.0008$ ) relative to test day 1 (Fig. 1a).

Blackbirds conditioned with $\mathrm{NHCl}$ (Fig. 1b) manifest conditioned color avoidance only (Tukey $p=0.0001$ ), but not conditioned flavor avoidance (Tukey $p=0.0689$ ), subsequent to $\mathrm{NHCl}$ conditioning. Average consumption of red and blue rice was $2.4 \mathrm{~g}( \pm 0.5)$ and $6.6 \mathrm{~g}$ $( \pm 0.6)$, respectively, and average consumption of rice treated with $\mathrm{NaCl}$ and citric acid was $3.5 \mathrm{~g}( \pm 0.6)$ and $5.6 \mathrm{~g}( \pm 0.5)$, respectively (Fig. 1b). Thus, we observed a cue-by-test group interaction for the red, $\mathrm{NaCl}, \mathrm{NHCl}$ conditioning group $(F(3,28)=11.65, p=0.0001)$. We did not observe a cue-test group-day interaction $(F(12,114)=1.04$, $p=0.4179$ ).

\section{Experiment two}

\subsection{Method}

We compared food avoidance conditioned with an anthraquinone(Avipel ${ }^{\circledR}$; Arkion Life Sciences, New Castle, DE), methiocarb- (Mesurol ${ }^{\circledR}$ 75 W; Gowan Co., Yuma, AZ), or methyl anthranilate-based repellent (Bird Shield ${ }^{\mathrm{TM}}$; Bird Shield Repellent Corp., Spokane, WA) to evaluate the effects of varying consequences of treated food. The modes of action of these active ingredients include a cathartic, emodin purgative [anthraquinone; 8]; a cholinesterase inhibitor (methiocarb; Gowan Co., EPA Reg. \#10163-231); and a trigeminal irritant [methyl anthranilate; 9]. We captured 66 adult red-winged blackbirds (M) near Fort Collins, CO and transported them to NWRC. We transferred birds to individual cages following group quarantine and holding, and offered each bird unadulterated seed rice (ad libitum) in each of two food bowls for 5 days (Wed-Sun).

Following acclimation, we offered each bird two food bowls at 0800-0930 h daily for two pretreatment days (Mon-Tue). Both food bowls contained $30 \mathrm{~g}$ of seed rice treated with blue pigment and citric acid (Table 2). Seed treatments included formulations of Experiment 1. We randomly assigned conditioning treatments among three groups ( $\mathrm{n}=22$ birds per each of 3 conditioning groups) at the conclusion of the pretreatment.

We replaced the pretreatment diet with two new food bowls at 0800-0930 h on Wednesday. Both food bowls contained $30 \mathrm{~g}$ of seed rice treated with red pigment and $\mathrm{NaCl}$ (Table 2). Seed treatments also included 0.5\% anthraquinone (Arkion Life Sciences), 0.125\% methiocarb [10], or 1\% methyl anthranilate [11] for conditioning groups 1-3, respectively (Table 2). We measured rice consumption at 0800 $0930 \mathrm{~h}$ on Thursday. For each conditioning group, we ranked blackbirds based upon conditioning rice consumption and assigned them to one of two test groups ( $n=11$ birds per each of 6 test groups). We randomly assigned test cues among groups. We provided maintenance food ( 2 millet: 1 milo: 1 safflower: 1 sunflower; ad libitum) in each of two food bowls to all birds for four days (Thur-Sun) following conditioning.

We offered two food bowls ( $30 \mathrm{~g}$ rice each) at 0800-0930 h, daily for four days of preference testing (Mon-Thur). For conditioning groups $1-3$, we evaluated color preference with test groups $1 \mathrm{~A}, 2 \mathrm{~A}$, and $3 A$, respectively (Table 2 ). We evaluated flavor preference with test groups 1B, 2B, and 3B. The north-south placement of food bowls was randomized on the first day and alternated on subsequent days of the preference test. We measured daily rice consumption, and accounted for rice spillage and desiccation throughout preference testing (Tue-Fri).

\subsection{Results and discussion}

Blackbirds conditioned with the anthraquinone-based repellent (Fig. 2a) manifest both conditioned color avoidance (Tukey $p=0.0001$ ) and conditioned flavor avoidance (Tukey $p=0.0007$ ) during the test. Average consumption of red and blue rice was $0 \mathrm{~g}( \pm 0.0)$ and $8.9 \mathrm{~g}$ $( \pm 0.4)$, respectively, and average consumption of rice treated with $\mathrm{NaCl}$ and citric acid was $2.5 \mathrm{~g}( \pm 0.9)$ and $6.8 \mathrm{~g}( \pm 0.8)$, respectively (Fig. 2a). Thus, we observed a cue-by-test group interaction for the red, $\mathrm{NaCl}$, anthraquinone conditioning group $(F(3,19)=45.13, p=0.0001)$. We did not observe a cue-test group-day interaction $(F(12,78)=0.17$, $p=0.9991$ ).

\section{Table 2}

Schedule for conditioning ( $\mathrm{n}=22$ birds per conditioning group) and preference testing ( $\mathrm{n}=11$ birds per test group) associated with conditioned avoidance among redwinged blackbirds in Experiment 2.

\begin{tabular}{|c|c|c|c|}
\hline Experiment 2 & Color cue & Flavor cue & Consequence \\
\hline Pretreatment exposure ( 2 days) & Blue & Citric acid & \\
\hline \multicolumn{4}{|l|}{ Conditioning ( 1 day) } \\
\hline Group 1 & Red & $\mathrm{NaCl}$ & Anthraquinone \\
\hline Group 2 & Red & $\mathrm{NaCl}$ & Methiocarb \\
\hline Group 3 & Red & $\mathrm{NaCl}$ & $\begin{array}{l}\text { Methyl } \\
\text { anthranilate }\end{array}$ \\
\hline \multicolumn{4}{|l|}{ Preference testing (4 days) } \\
\hline \multicolumn{4}{|l|}{ Color preference test } \\
\hline Group 1A & Red vs blue & & \\
\hline Group 2A & Red vs blue & & \\
\hline Group 3A & Red vs blue & & \\
\hline \multicolumn{4}{|l|}{ Flavor preference test } \\
\hline Group 1B & & $\begin{array}{l}\mathrm{NaCl} \text { vs } \\
\text { citric acid }\end{array}$ & \\
\hline Group 2B & & $\begin{array}{l}\mathrm{NaCl} \text { vs } \\
\text { citric acid }\end{array}$ & \\
\hline Group 3B & & $\begin{array}{l}\mathrm{NaCl} \text { vs } \\
\text { citric acid }\end{array}$ & \\
\hline
\end{tabular}

Conditioning groups 1, 2, and 3 were conditioned with an anthraquinone-, methiocarb-, and methyl anthranilate-based repellent, respectively, to avoid an otherwise preferred color (red) and neutral flavor $(\mathrm{NaCl})$. Daily food consumption in each of two food bowls was measured to evaluate color preference (test groups $1 \mathrm{~A}, 2 \mathrm{~A}$, and $3 \mathrm{~A}$ ) and flavor preference (test groups $1 \mathrm{~B}, 2 \mathrm{~B}$, and $3 \mathrm{~B}$ ) subsequent to conditioning. 
a

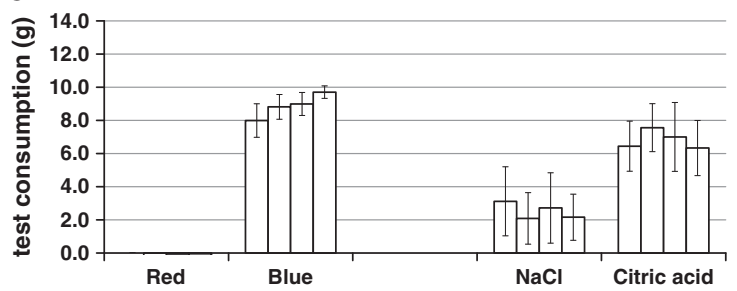

b

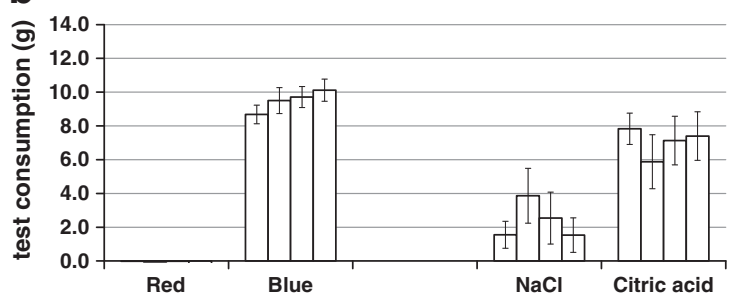

C

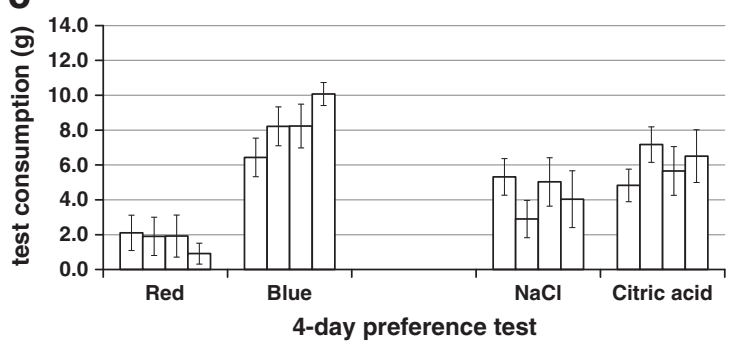

Fig. 2. Color and flavor preferences among red-winged blackbirds subsequent to free-choice conditioning with an (a) anthraquinone-based repellent $(n=15)$, (b) methiocarb-based repellent $(\mathrm{n}=19)$, or (c) methyl-anthranilate based repellent $(\mathrm{n}=21)$ paired with an otherwise preferred color (red) and an otherwise neutral flavor $(\mathrm{NaCl})$. Data represent average $( \pm \mathrm{SE})$ daily rice consumption during 4 test days subsequent to repellent conditioning.

Blackbirds conditioned with the methiocarb-based repellent (Fig. 2b) also manifest both conditioned color avoidance (Tukey $p=0.0001$ ) and conditioned flavor avoidance (Tukey $p=0.0001$ ) during the test. Average consumption of red and blue rice was $0 \mathrm{~g}$ $( \pm 0.0)$ and $9.5 \mathrm{~g}( \pm 0.3)$, respectively, and average consumption of rice treated with $\mathrm{NaCl}$ and citric acid was $2.4 \mathrm{~g}( \pm 0.6)$ and $7.1 \mathrm{~g}$ $( \pm 0.7)$, respectively (Fig. $2 b)$. Thus, we observed a cue-by-test group interaction for the red, $\mathrm{NaCl}$, methiocarb conditioning group $(F(3,25)=82.90, p=0.0001)$. We did not observe a cue-test groupday interaction $(F(12,102)=0.59, p=0.8488)$.

Blackbirds conditioned with the methyl anthranilate-based repellent (Fig. 2c) manifest conditioned color avoidance (Tukey $p=0.0001$ ), but not conditioned flavor avoidance (Tukey $p=0.2080$ ), subsequent to ingesting methyl anthranilate. Average consumption of red and blue rice was $1.7 \mathrm{~g}( \pm 0.5)$ and $8.2 \mathrm{~g}( \pm 0.5)$, respectively, and average consumption of rice treated with $\mathrm{NaCl}$ and citric acid was $4.3 \mathrm{~g}( \pm 0.6)$ and $6.0 \mathrm{~g}( \pm 0.6)$, respectively (Fig. 2c). Thus, we observed a cue-by-test group interaction for the red, $\mathrm{NaCl}$, methyl anthranilate conditioning group $(F(3,28)=22.73, p=0.0001)$. We did not observe a cue-test group-day interaction $(F(12,114)=0.85, p=0.5982)$.

\section{Experiment three}

\subsection{Method}

We compared food avoidance conditioned with the postingestive repellents used in Experiment 2 when tested with novel comparison cues. To do so, blue and citric acid rice seed treatments were absent prior to testing. Thus, unadulterated rice seed was provided prior to conditioning (i.e., acclimation; Table 3).

We captured 44 adult red-winged blackbirds (M) near Fort Collins, $\mathrm{CO}$ and transported them to NWRC. We transferred birds to individual cages following group quarantine and holding, and offered each bird $80 \mathrm{~g}$ of unadulterated seed rice in each of two food bowls for 7 days (Wed-Tue). We measured rice consumption at $0800-0930 \mathrm{~h}$ on Tuesday. We ranked blackbirds based upon rice consumption observed prior to conditioning. We assigned birds to one of two groups $(\mathrm{n}=22$ birds per each of 2 conditioning groups) and randomly assigned treatments between groups.

We replaced the pretreatment diet with two new food bowls at 0800-0930 h on Wednesday. Both food bowls contained $30 \mathrm{~g}$ of seed rice treated with red pigment and $\mathrm{NaCl}$ (Table 3 ) and seed treatments included formulations of Experiments 1 and 2. Seed treatments also included $0.5 \%$ anthraquinone (Arkion Life Sciences) or 0.125\% methiocarb [10] for conditioning groups 1 and 2, respectively (Table 3). We measured rice consumption at $0800-0930 \mathrm{~h}$ on Thursday. For each conditioning group, we ranked blackbirds based upon conditioning rice consumption and assigned them to one of two test groups ( $\mathrm{n}=11$ birds per each of 4 test groups). We randomly assigned test cues among groups. We provided maintenance food ( 2 millet: 1 milo: 1 safflower: 1 sunflower; ad libitum) in each of two food bowls to all birds for four days (Thur-Sun) following conditioning.

We offered two food bowls ( 30 g rice each) at 0800-0930 h, daily for four days of preference testing (Mon-Thur). For conditioning groups 1 and 2, we evaluated color preference with test groups $1 \mathrm{~A}$ and $2 \mathrm{~A}$, respectively (Table 3 ). We evaluated flavor preference with test groups $1 \mathrm{~B}$ and $2 \mathrm{~B}$. The north-south placement of food bowls was randomized on the first day and alternated on subsequent days of the preference test. We measured daily rice consumption, and accounted for rice spillage and desiccation throughout preference testing (Tue-Fri).

\subsection{Results and discussion}

Blackbirds conditioned with the anthraquinone-based repellent (Fig. 3a) did not manifest either conditioned color or flavor avoidance when comparison cues (blue, citric acid) were absent prior to testing $(F(3,28)=0.63, p=0.6015)$. Average consumption of red and blue rice was $3.8 \mathrm{~g}( \pm 0.8)$ and $4.1 \mathrm{~g}( \pm 0.9)$, respectively, and average consumption of rice treated with $\mathrm{NaCl}$ and citric acid was $5.1 \mathrm{~g}( \pm 0.7)$ and $5.0 \mathrm{~g}( \pm 0.7)$, respectively. We did not observe a cue-test groupday interaction $(F(12,114)=1.56, p=0.1143)$.

Table 3

Schedule for conditioning ( $\mathrm{n}=22$ birds per conditioning group) and preference testing ( $\mathrm{n}=11$ birds per test group) associated with conditioned avoidance among redwinged blackbirds in Experiment 3.

\begin{tabular}{llll}
\hline Experiment 3 & Color cue & Flavor cue & Consequence \\
\hline Acclimation (7 days) & $\begin{array}{l}\text { Unadulterated } \\
\text { rice seed }\end{array}$ & $\begin{array}{l}\text { Unadulterated } \\
\text { rice seed }\end{array}$ & \\
$\begin{array}{l}\text { Conditioning (1 day) } \\
\text { Group 1 }\end{array}$ & Red & $\mathrm{NaCl}$ & $\begin{array}{l}\text { Anthraquinone } \\
\text { Methiocarb }\end{array}$ \\
$\begin{array}{l}\text { Group 2 } \\
\text { Preference testing (4 days) } \\
\text { Color preference test }\end{array}$ & Red & $\mathrm{NaCl}$ & \\
$\quad$ Group 1A & Red vs blue & & \\
$\quad$ Group 2A & Red vs blue & & \\
Flavor preference test & & $\mathrm{NaCl}$ vs & \\
$\quad$ Group 1B & & citric acid & \\
Group 2B & & NaCl vs & \\
& & citric acid & \\
\hline
\end{tabular}

Conditioning groups 1 and 2 were conditioned with an anthraquinone- and methiocarb-based repellent, respectively, to avoid an otherwise preferred color (red) and neutral flavor $(\mathrm{NaCl})$. Daily food consumption in each of two food bowls was measured to evaluate color preference (test groups $1 \mathrm{~A}$ and $2 \mathrm{~A}$ ) and flavor preference (test groups $1 \mathrm{~B}$ and $2 \mathrm{~B}$ ) subsequent to conditioning. 
a

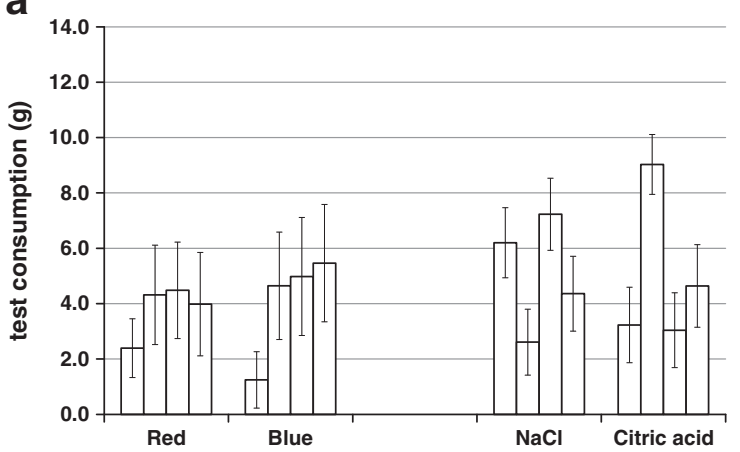

b

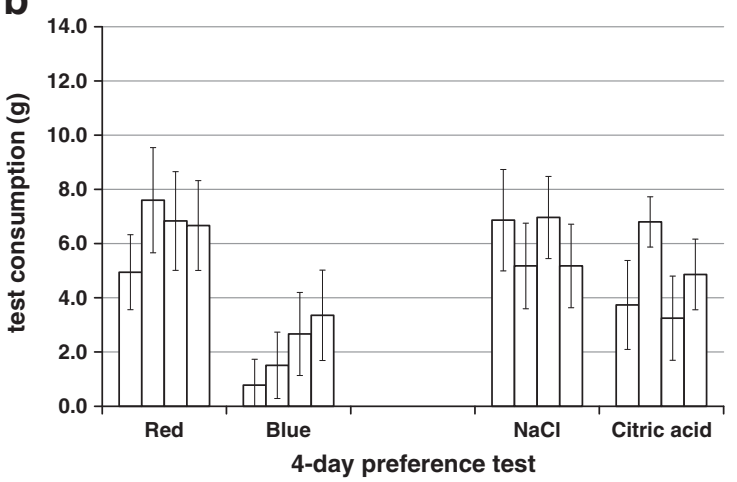

Fig. 3. Color and flavor preferences among red-winged blackbirds subsequent to free-choice conditioning with an (a) anthraquinone-based repellent $(n=21)$ or (b) methiocarb-based repellent $(n=17)$ paired with an otherwise preferred color (red) and an otherwise neutral flavor $(\mathrm{NaCl})$. Comparison cues (blue, citric acid) were made absent prior to the test. Data represent average $( \pm S E)$ daily rice consumption during 4 test days subsequent to repellent conditioning.

Blackbirds conditioned with the methiocarb-based repellent (Fig. 3b) also did not manifest either conditioned color or flavor avoidance when comparison cues (blue, citric acid) were absent prior to testing. Blackbirds consumed an average of $6.5 \mathrm{~g}( \pm 0.8)$ of red rice and $2.1 \mathrm{~g}( \pm 0.7)$ of blue rice during the preference test (Tukey $p=0.0024)$. Thus, we observed a cue-by-test group interaction $(F(3$, $22)=6.73, p=0.0022$ ). Average consumption of rice treated with $\mathrm{NaCl}$ and citric acid was $6.0 \mathrm{~g}( \pm 0.8)$ and $4.7 \mathrm{~g}( \pm 0.7)$, respectively (Tukey $p=0.6298$; Fig. 3b). We did not observe a cue-test group-day interaction $(F(12,90)=0.61, p=0.8285)$.

\section{General discussion}

These experiments illustrate the applicability of cue-consequence specificity to red-winged blackbirds. Consistent with cue-consequence specificity (hypothesis 1 ), blackbirds reliably avoided flavor cues previously paired with gastrointestinal toxicosis $(\mathrm{LiCl})$ and color cues previously paired with peripheral distress $(\mathrm{NHCl})$ in Experiment 1. Unlike our predictions associated with cue-consequence specificity exhibited among rats, blackbirds also avoided color cues previously associated with $\mathrm{LiCl}$ in this and our previous study [5].

Consistent with hypotheses 2 and 3 regarding primary and secondary repellents, blackbirds did not avoid flavor cues previously paired with a trigeminal irritant (methyl anthranilate), and they avoided flavor and color cues previously paired with the postingestive repellents in Experiment 2. Unlike our prediction associated with primary repellents (hypothesis 2), blackbirds avoided color cues conditioned with methyl anthranilate. Based upon the predicted and unpredicted results of Experiments 1 and 2, we conclude that blackbirds cognitively associate pre- and postingestive consequences with visual cues.
Although cholinesterase inhibition induced by methiocarb does not directly induce gastrointestinal toxicosis, postingestive consequences of anthraquinone and methiocarb likely include enhanced gut motility, malabsorption, and dehydration [12]. Although methyl anthranilate is a trigeminal irritant, enteric delivery of methyl anthranilate yields repellent efficacy comparable to that of methiocarb [13]. Indeed, repellents based merely on offensive flavors are not likely to be effective in the absence of aversive postingestive effects and the reason that many wildlife repellents are effective only temporarily is because they merely change the flavors of familiar foods (i.e., novelty effects) [14].

We predicted that blackbirds would avoid novel flavor cues (not novel color cues) subsequent to conditioning with the postingestive repellents (hypothesis 4). However, blackbirds did not avoid redcolored or $\mathrm{NaCl}$-flavored rice previously associated with anthraquinone or methiocarb when comparison cues (blue, citric acid) were made absent prior to the test of Experiment 3. Indeed, blackbirds resumed baseline preference for red rice subsequent to methiocarb conditioning when provided with a novel alternative (blue) during the test.

Our following results can be applied in context of agricultural damage management: blackbirds cognitively associate pre- and postingestive consequences with visual cues, and blackbirds reliably integrate visual and gustatory experience with postingestive consequences to procure nutrients and avoid toxins. For the purpose of protecting newly planted $[12,15]$ and ripening crops from blackbird depredation [16-19], we recommend application(s) and the presence of flavor and/or color cues sufficiently similar to the applied, postingestive repellent throughout the period of needed crop protection. For example, anthraquinone absorbs near-ultraviolet light [20] visible to most birds [21] and it is a postingestive, cathartic purgative [8]. Thus, an effective repellent application strategy might include initial applications of a postingestive repellent (e.g., anthraquinone) and subsequent applications of a visual cue with spectral characteristics (e.g., near-ultraviolet absorbance) sufficiently similar to the repellent (Werner, 2010; Ultraviolet Strategy for Avian Repellency, U.S.A. patent application \#12/652,944).

\section{Acknowledgments}

We thank T.C. Atwood, S.M. Jojola, B.A. Kimball, G.M. Linz, S.E. Pettit, M.E. Tobin, and J.K. Young for their thoughtful comments regarding an earlier version of this manuscript. We also thank S.K. Tupper and K. Romer for their dedicated laboratory assistance, and J.C. Hurley for his applied understanding of aluminum lake dispersions. We appreciate the NWRC animal care staff that provided daily care throughout our feeding experiments. The capture, care, and use of animals associated with feeding experiments were approved by NWRC's Institutional Animal Care and Use Committee (NWRC Study Protocol QA1454, S.J. Werner - Study Director).

\section{References}

[1] Provenza FD. Postingestive feedback as an elementary determinant of food preference and intake in ruminants. J Range Manage 1995;48:2-17.

[2] Garcia J, Koelling RA. Relation of cue to consequence in avoidance learning. Psychon Sci 1966;4:123-4.

[3] Lett BT. The pain-like effect of gallamine and naloxone differs from sickness induced by lithium chloride. Behav Neurosci 1985;99:145-50.

[4] Wilcoxon HC, Dragoin WB, Kral PA. Illness-induced aversions in rat and quail: relative salience of visual and gustatory cues. Science 1971;171:826-8.

[5] Werner SJ, Kimball BA, Provenza FD. Food color, flavor, and conditioned avoidance among red-winged blackbirds. Physiol Behav 2008;93:110-7.

[6] Clark L. Physiological, ecological, and evolutionary bases for the avoidance of chemical irritants by birds. Current Ornith 1998;14:1-37.

[7] Rogers Jr JG. Responses of caged red-winged blackbirds to two types of repellents. J Wildl Manage 1974;38:418-23.

[8] Merck Veterinary Manual. 7th ed. 1991.

[9] Clark L, Mason JR. Interaction between sensory and postingestional repellents in starlings: methyl anthranilate and sucrose. Ecol Appl 1993;3:262-70. 
[10] Mason JR, Reidinger RF. Importance of color for methiocarb-induced food aversions in red-winged blackbirds. J Wildl Manage 1983;47:383-93.

[11] Avery ML, Decker G, Fischer DL, Aronov E, Linscombe SD. Methyl anthranilate as a rice seed treatment to deter birds. J Wildl Manage 1995;59:50-6.

[12] Werner SJ, Carlson JC, Tupper SK, Santer MM, Linz GM. Threshold concentrations of an anthraquinone-based repellent for Canada geese, red-winged blackbirds, and ring-necked pheasants. Appl Anim Behav Sci 2009;121:190-6.

[13] Sayre RW, Clark L. Effect of primary and secondary repellents on European starlings: an initial assessment. J Wildl Manage 2001;65:461-9.

[14] Provenza FD. Origins of food preference in herbivores. In: Mason JR, editor. Repellents in wildlife management: proceedings of a symposium. Fort Collins: National Wildlife Research Center; 1997. p. 81-90.

[15] Werner SJ, Cummings JL, Tupper SK, Hurley JC, Stahl RS, Primus TM. Caffeine formulation for avian repellency. J Wildl Manage 2007;71:1676-81.
[16] Werner SJ, Homan HJ, Avery ML, Linz GM, Tillman EA, Slowik AA, et al. Evaluation of Bird Shield ${ }^{\mathrm{TM}}$ as a blackbird repellent in ripening rice and sunflower fields. Wildl Soc Bull 2005;33:251-7.

[17] Werner SJ, Cummings JL, Pipas PA, Tupper SK, Byrd RW. Registered pesticides and citrus terpenes as blackbird repellents for rice. J Wildl Manage 2008;72:1863-8.

[18] Werner SJ, Cummings JL, Tupper SK, Goldade DA, Beighley D. Blackbird repellency of selected registered pesticides. J Wildl Manage 2008;72:1007-11.

[19] Werner SJ, Linz GM, Tupper SK, Carlson JC. Laboratory efficacy of chemical repellents for reducing blackbird damage in rice and sunflower crops. J Wildl Manage 2010;74:1400-4.

[20] Du H, Fuh RA, Li J, Corkan A, Lindsey JS. PhotochemCAD: a computer aided design and research tool in photochemistry. Photochem Photobiol 1998;68:141-2.

[21] Hart NS, Hunt DM. Avian visual pigments: characteristics, spectral tuning, and evolution. Am Nat 2007;169(suppl):S7-S26. 